\title{
Statistical Models for Web Pages Usability
}

\author{
Saad Subair, Hussah AlEisa \\ College of Computer and Information Sciences, Princess Nourah bint Abdulrahman University, Riyadh, KSA \\ Email: ssubair@gmail.com
}

Received 14 November 2015; accepted 22 February 2016; published 25 February 2016

Copyright (C) 2016 by authors and Scientific Research Publishing Inc.

This work is licensed under the Creative Commons Attribution International License (CC BY). http://creativecommons.org/licenses/by/4.0/

(c) (i) Open Access

\begin{abstract}
The usability of an interface is a fundamental issue to elucidate. Many researchers argued that many usability results and recommendations lack empirical and experimental data. In this research, the usability of the web pages is evaluated using several carefully selected statistical models. Universities web pages are chosen as subjects for this work for ease of comparison and ease of collecting data. A series of experiments has been conducted to investigate into the usability and design of the universities web pages. Prototype web pages have been developed according to the structured methodologies of web pages design and usability. Universities web pages were evaluated together with the prototype web pages using a questionnaire which was designed according to the Human Computer Interactions (HCI) heuristics. Nine (users) respondents' variables and 14 web pages variables (items) were studied. Stringent statistical analysis was adopted to extract the required information to form the data acquired, and augmented interpretation of the statistical results was followed. The results showed that the analysis of variance (ANOVA) procedure showed there were significant differences among the universities web pages regarding most of the 23 items studied. Duncan Multiple Range Test (DMRT) showed that the prototype usability performed significantly better regarding most of the items. The correlation analysis showed significant positive and negative correlations between many items. The regression analysis revealed that the most significant factors (items) that contributed to the best model of the universities web pages design and usability were: multimedia in the web pages, the web pages icons (alone) organisation and design, and graphics attractiveness. The results showed some of the limitations of some heuristics used in conventional interface systems design and proposed some additional heuristics in web pages design and usability.
\end{abstract}

\section{Keywords}

Usability, HCI, Web Pages Interface, Statistical Models, Ergonomics

\section{Introduction}

User interface is a system layer through which the computer and users communicate [1]-[3]. It is an essential 
part of human computer interaction (HCI). A survey conducted by Myers and Rosson [4] showed that software development devoted almost half of the code to the user interface [4] [5]. Dealing with or achieving goals using the interface is known as the usability of the interface. Usability of a system is how easy the system to use and how easy and efficient to perform task [6]-[8].

The Web is a huge communication system. From a technical point of view, the Web is a system of exchanging data over computer networks using special software. The interfaces used in the web pages are graphical user interfaces that utilize graphics, colours, and icons. Researches showed that there is still a big gap between the researches of the Human Computer Interaction (HCI) and hypertext systems, essentially the web [9]. Shneiderman [6] [10] argued that many researchers' experience lack empirical data to validate or solidify their conclusions. Web sites can be well categorized by the originator's identity such as individual group, university, corporation, and non-profit organization [10]. Information about users can guide web designers to a better design.

The problems that inspired the research of this study can be listed as follows:

1. There were no empirical studies that categorized the users of the universities web pages, studied their preference, and the problems they were facing when using these web pages.

2. To specify the relative importance of some items or parameters of interface design and usability.

The main objective of this study is to investigate into the relations between the items of web pages design and usability and point out which items or variables contribute significantly to web pages design of the universities.

The hypothesis of this study is that:

1. There are significant differences in the design and development of web pages interfaces among the universities;

2. A prototype of a university sample web pages may stimulate and inspire well-structured procedural web pages interface design;

3. Empirical data from a questionnaire and statistical analysis of these data is expected to lead to conclusions and recommendations about the user preference and design aspects of the universities web pages.

The study was focused on the design and development of user interface for the web pages of the universities. The contents of the web pages (the text and the issues inside) were not subjected to detailed studies.

Buckingham and McKnight [9] and Lee and Kozar, [11] reviewed several articles on the web usability and concluded that the link between the hypertext and the web is getting closer. Bieber et al. [12] predicted the evolution of the Web. They examined an array of hypertext technologies which have yet to be adopted in the web development. Smith et al. [13] discussed the information structuring and searching in the Web and reviewed their common problems. Erskine et al. [14] described the application to web site redesign of an adapted form of scenario-based design through claims analysis. Their approaches were contrasting with other theoretical approaches found in the HCI field. They presented a case study of web site redesign which illustrated how scenarios can serve as tools of building interactivity. In a comparative analysis of book-based text and hypertext, Thimble by [15] argued that comprehensive, iterative design and testing (the conventional system development life cycle) of Web structures soon becomes impractical without good authoring tools. He described a tool for Web authoring which uses a page layout language and database of pages to relieve cognitive overhead for authors. Studying distance learning on the web, Benyon et al. [16] presented a case study of iterative, courseware design. They discussed the different presentation and linking constraints imposed by mark-up tools and browser technology. They concluded that before the web-based learning become a practical and effective option, better authoring tools and clearer pedagogical design principles are needed. The knowledge and experience already gained in other user interface design domains such as menu systems and hypertext [7] [17]-[21] and the results of the research in information retrieval systems [22] [23] can be helpful in web design till empirical data and cases accumulate and give solid and clear methodologies for web pages design. Two of the most important issues in web pages design are length and number of links in web pages. Icon, home, or index page to point to fragments is necessary. Meaningful structures that guide users to the fragments they want is the goal, but excessive fragmentation disrupts those who wish to read or print the full text. Providing users with a visual overview of the web site may reduce the disorientation of the web pages which is a result of adding new materials to the web pages [6]. Staggers [24] suggested that compact vertical design within a page to reduce scrolling of pages can be helpful in web pages design. Some white space can help organize a display of a page. Using excessive horizontal rules or blank lines to separate items is a common mistake in web pages design [25]. Shneiderman [10] suggested that sequencing, clustering, and emphasis for objects within a page are very important issues to consider. The first object in a page is expected to be an important item and likely to be selected (Object/Ac- 
tion). Clustering related items shows meaningful annotation and relationships between them. Important items can be emphasized with large fonts, color highlights, and surrounding boxes. Questionnaires were used to evaluate the usability of interfaces [26]. However, researchers found problems and weaknesses in the questionnaires developed in the past [10] [27]-[31]. The problems varied from non-represented population sample, to lack of validation and low reliabilities of the questionnaires. Users' acceptance or subjective satisfaction of a system is a critical measure of the system success. Chin et al. [29] developed a measurement instrument which measures the user's subjective rating of the human computer interface called the Questionnaire for User Interface Satisfaction (QUIS). Improvements to the questionnaires for evaluating computer systems were introduced when the sample size and the number of different systems to evaluate were increased [32]. According to the Psychometric Theory the reliability of a questionnaire can be increased by increasing the number of items and scaling steps or points, but much many steps on the scale may affect its reliability adversely (Nunnally [33]).

\section{Methodology}

In this study, the problems and the objectives of this research which are stated earlier were attempted to be solved or achieved through:

1. Designing and developing a prototype user interface for a university web page using recent web pages development methodologies.

2. Making the necessary amendments and improvements to the prototype.

3. Evaluating the prototype and other universities web pages interface in a comparative approach through a questionnaire.

4. Using the analysis of variance (ANOVA) procedure to point out the significant differences among the universities web pages with regard to each item (variable) of web pages design.

5. Using correlation analysis to investigate the relationship and association between (items) of universities web pages design variable (each two at a time) as well as multiple relationships

6. Using regression analysis to investigate the causality relationships to find out the most significant independent variables (items) that form the best model or models for the universities web pages design.

Like other computer programs, user interface systems go through stages or phases of development life cycle. In general, the phases that are usually followed in developing user interface systems are similar to those of conventional information system development life cycle with minor modifications. However, Nielsen [2] suggested the usability engineering lifecycle to be particularly applied to interface development and evaluation. The art of prototyping was followed in this study. The first prototype was further improved in sequence till it reached an acceptance level. The first prototype was planned to be a fast design using as little resources as possible. Although HTML is fairly easy programming language, enabling images and adjusting the layouts was somewhat tedious and time consuming. The very first prototype was a scenario where both the different features and functions of the web pages were reduced or cut down. At the next step, this scenario was extended to a horizontal prototype where the surface layer or layout of the web pages (front pages) was in its complete form but the links were not linked to real data or information. In this stage, the concept of prototyping was utilized to the best.

As in conventional system development methodologies, iteration was essential in this design. Most of the steps that were followed needed to be revised. This made the iteration an inevitable process in this design. However, the iteration was done carefully since some iteration might revert the usability of the prototype to some poor usability levels. Shneiderman's Objects/Actions Interface (OAI) Model which follows a hierarchical decomposition of objects and actions in the task and interface domains is considered to decompose complex information problem and building a comprehensible and effective prototype. The benefits from this model were centered in building the required interface objects for the prototype and specifying the required actions on that objects.

\subsection{The Experiment}

After the prototype was developed, an experiment was conducted to investigate into the usability aspects of four universities web pages and the prototype interface design. The universities are:

1. Univ1;

2. Univ2; 


\section{Univ3;}

4. Univ4;

5. The prototype.

The experiment was a comparative evaluation of the usability problems of these web pages. A sample of 59 students was given a questionnaire to respond to. The students were given enough time to go through and navigate all the five web pages and then asked to attempt answering the questions of the questionnaire. The questions of the questionnaire were mainly designed to point out the usability aspects or attributes of the universities web pages interfaces. The computer laboratory where the experiment was conducted was organized in a way that each user will be independent in his navigation of the web pages and his response to the questions. More than one lab was used for the experiment or evaluation. The evaluation environment was kept to be as normal as possible. Since the test took considerable time (1 to 2 hours), the experiment was conducted in sessions and the users were left free to have a break at any time and respond to the questions in a relax way. The users were informed clearly that all the answers to the questionnaire questions are for the sake of evaluating the web pages and not the users and any preliminary data and personal information will be kept confidential. It is in the guidelines of the questionnaire that, the user may not write his/her name if he/she wishes to.

The answer sheets of the questionnaire were collected after the users finished answering the questions and the data was transferred to the SPSS (Statistical package for social sciences) to be analyzed statistically.

The questionnaire was designed using a rating scale ascending from 1 to 5 which was designed to be administered at controlled experimental conditions. The questions were designed such that each question represents an item of design or heuristic of the interface for the universities web pages. The response of the user (respondent) shows his preference or judgement level of that item. Each item was considered as a variable contributing to the web pages design.

\subsection{Items (Variables) Studied}

In this study, 23 items or variables were designed as questions in the questionnaire and assigned to the five point scale described before. Nine of the 23 items were concerned with the respondents' knowledge background while the other 14 variables were items of web pages design. The 23 items are listed below.

(a) Respondents Knowledge Background

1. Respondents computer exposure;

2. Respondents internet exposure;

3. Respondents universities web pages exposure;

4. Importance of looking up information on universities in the Internet;

5. Respondents trust of web pages information;

6. Respondents music preference in the universities web pages;

7. Respondents animated pictures preference in the universities web pages;

8. Respondents graphics preference in the universities web pages;

9. Importance of developing web pages for the universities.

\section{(b) Items (Variables) of Web Pages Design}

1. Color amount;

2. Contrast against the background;

3. Graphics information provision;

4. Color and Graphics feel of Consistency;

5. Navigation;

6. Location tracking inside the web pages;

7. Hyperlinks (hotspot) semantics;

8. Forms organization and helpfulness;

9. Animated pictures effect on web pages look;

10. Text (alone) organization and design;

11. Icons (alone) organization and design;

12. Icons and text organization and design;

13. Multimedia preference;

14. Universities web pages ranking. 


\subsection{Statistical Analysis}

The data was collected from the questionnaire answer sheets and coded and transferred into SPSS ${ }^{\circledR}$ statistical package to obtain the statistical analysis for the descriptive statistics of the sample, the analysis of variance (ANOVA) of the universities web pages, and the correlation analysis of the items (variables). The data was then converted into text file and uploaded to the university's mainframe to use SAS ${ }^{\circledR}$ statistical package to obtain the regression analysis output which is clearer in $\mathrm{SAS}^{\circledR}$. Interpretations of all these statistical measures would reveal the significant difference among the universities web pages interface design for each item and point out the better items or variables for the universities web pages design.

\subsection{Analysis of Variance Procedure}

The ANOVA partitions the source of variations into within groups and between groups variation to obtain the F-value which in turn determines whatever to accept or reject the null hypothesis. The analysis of variance (ANOVA) table will then look as illustrated in Table 1.

Duncan's multiple range test (DMRT) was used to test the differences between groups (universities).

\subsection{Correlation Analysis}

Simple correlation between the nine respondents' computer and Internet level background items (variable) and the 23 items of universities web pages design (independently) were calculated from the original data using SPSS. The correlation coefficient ( $\mathrm{r}$ ) between two characters (X and $\mathrm{Y}$ ) is usually expressed as follows:

$$
r=\frac{\sum x y}{\sqrt{\left(\sum x^{2}\right)\left(\sum y^{2}\right)}}
$$

where

$$
\begin{aligned}
& x=\mathrm{X}-\mathrm{X} \text { and } \mathrm{y}=\mathrm{y}-\mathrm{Y} \text { and } \\
& \mathrm{x}=\text { Independent variable (item); } \mathrm{X} \text { is the mean of character } \mathrm{X} . \\
& \mathrm{y}=\text { Independent variable (item); } \mathrm{Y} \text { is the mean of character } \mathrm{Y} \text {. }
\end{aligned}
$$

\subsection{Regression Analysis}

Simple and multiple linear regressions of some items (independent variables) on the ranking of the university web pages item (dependent variable) were estimated. The formula for multiple linear regression is as follows:

$$
Y=a+b_{1} X_{1}+b_{2} X_{2}+\cdots+b_{n} X_{n}
$$

where:

$Y=$ dependent variable;

$X_{1-n}=$ independent variables;

$a=$ intercept of the regression line on the $\mathrm{Y}$ axis;

$b_{1-n}=$ linear regression coefficients;

$n=\mathrm{N}$ Univ3ber of independent variables.

Backward, forward, and stepwise selection regression analysis has also been attempted. In stepwise selection variables are added (or removed) one by one into (from) the model. F-statistic is calculated after a variable is added into (or removed from) the model. A variable that did not produce significant F-value at a redefined probability level is then deleted from (or added to) the model. In forward selection, variables already in the model

\section{Table 1. Analysis of variance (ANOVA) table based on individual observations ${ }^{c}$.}

\begin{tabular}{cccc}
\hline Source of variation & $\mathrm{df}^{\mathrm{a}}$ & Mean square (variance) & $\mathrm{F}_{(\text {Observed })}$ \\
\hline Between groups & $\mathrm{k}-1$ & Variance $_{\text {(Between groups) }}$ & Variance $_{(\text {Within groups) }}$ \\
Within groups (error) & $\mathrm{N}-\mathrm{k}$ & $\mathrm{N}-1$ & \\
Total & $\mathrm{N}$ & \\
\hline
\end{tabular}

${ }^{\mathrm{a}} \mathrm{k}=$ the $\mathrm{n}$ Univ3ber of groups; $\mathrm{N}=$ the total $\mathrm{n}$ Univ3ber of subjects in the study; ${ }^{\mathrm{b}}$ Significance level (probability level); ${ }^{\mathrm{c}}$ Adapted from (Shavelson, 1996). 
do not necessary stay there and the process ends when none of the variables outside the model is significantly contributing to the model at the specified probability level [34] [35].

\section{Results and Discussion}

In this article, the nine respondents' knowledge background variables will be discussed first followed by the 14 web pages variables.

\subsection{Respondents' Knowledge Background}

A correlation analysis study was used to explain the relationship between the nine variables of the respondents' knowledge background. Table 2 shows that respondents' computer exposure has positive significant correlation with the respondents' internet exposure, respondents' exposure to universities web pages, importance of looking up information about universities in the internet, and the importance of developing web pages for universities. However, respondents' computer exposure showed significant negative correlation with the respondents' preference to animation in universities web pages.

Respondents' internet exposure showed positive significant correlation with the respondents' exposure to universities web pages, respondents' trust of the information of the web, and the importance of developing web pages for universities. Meanwhile, respondents' internet exposure showed significant negative correlation with the respondents' music preference and animated pictures preference in the web pages of universities (Table 2). Table 2 also shows that respondents exposure to universities and importance of looking information about universities in the internet followed almost the same pattern of relation with the other variables as the previous variable respondents' internet exposure.

Table 2 also shows that respondents who trust information of the web believe in the importance of developing web pages for universities. It is also shown that respondents who prefer music in the universities web pages they also prefer animated pictures and graphics in the web pages of universities. However, Table 2 shows a negative

Table 2. Correlation coefficient of the 12 items (variables) of the respondents computers and Internet usage background.

\begin{tabular}{|c|c|c|c|c|c|c|c|c|}
\hline & $\begin{array}{l}\text { Respondents } \\
\text { computer } \\
\text { exposure }\end{array}$ & $\begin{array}{l}\text { Respondents } \\
\text { internet } \\
\text { exposure }\end{array}$ & $\begin{array}{l}\text { Respondents } \\
\text { exposure to } \\
\text { universities } \\
\text { web pages }\end{array}$ & $\begin{array}{c}\text { Importance } \\
\text { of looking } \\
\text { information } \\
\text { about } \\
\text { universities } \\
\text { in the internet }\end{array}$ & $\begin{array}{l}\text { Respondents } \\
\text { trust of the } \\
\text { information } \\
\text { of the web }\end{array}$ & $\begin{array}{l}\text { Respondents } \\
\text { music } \\
\text { preference } \\
\text { in the } \\
\text { universities } \\
\text { web pages }\end{array}$ & $\begin{array}{l}\text { Respondents } \\
\text { animation } \\
\text { pictures } \\
\text { preference } \\
\text { in the } \\
\text { universities } \\
\text { web pages }\end{array}$ & $\begin{array}{l}\text { Respondents } \\
\text { graphics } \\
\text { preference } \\
\text { in the } \\
\text { universities } \\
\text { web pages }\end{array}$ \\
\hline $\begin{array}{c}\text { Respondents } \\
\text { internet exposure }\end{array}$ & $0.52^{* *}$ & & & & & & & \\
\hline $\begin{array}{c}\text { Respondents exposure } \\
\text { to universities } \\
\text { web pages }\end{array}$ & $0.40^{* *}$ & $0.59^{* *}$ & & & & & & \\
\hline $\begin{array}{l}\text { Importance of } \\
\text { looking information on } \\
\text { universities in internet }\end{array}$ & $0.24^{* *}$ & 0.13 & $0.23^{* *}$ & & & & & \\
\hline $\begin{array}{l}\text { Respondents trust } \\
\text { of the information } \\
\text { of the web }\end{array}$ & $0.20^{* *}$ & $0.26^{* *}$ & $0.18^{*}$ & 0.11 & & & & \\
\hline $\begin{array}{l}\text { Respondents music } \\
\text { preference in the } \\
\text { universities web pages }\end{array}$ & -0.09 & $-0.17^{*}$ & 0.02 & $0.17^{*}$ & -0.08 & & & \\
\hline $\begin{array}{l}\text { Respondents animation } \\
\text { pictures preference in } \\
\text { universities web pages }\end{array}$ & $-0.19^{* *}$ & $-0.30^{* *}$ & -0.10 & - & -0.13 & $0.55^{* *}$ & & \\
\hline $\begin{array}{l}\text { Respondents graphics } \\
\text { preference in the } \\
\text { universities web pages }\end{array}$ & 0.05 & 0.05 & $0.14^{*}$ & 0.07 & - & $0.36^{* *}$ & $0.48^{* *}$ & \\
\hline $\begin{array}{c}\text { Importance of } \\
\text { developing web } \\
\text { pages for universities }\end{array}$ & $0.33^{* *}$ & $0.36^{* *}$ & $0.28^{* *}$ & $0.38^{* *}$ & $0.23^{* *}$ & -0.13 & $-0.21^{* *}$ & $0.20^{* *}$ \\
\hline
\end{tabular}


significant correlation between respondents animation preference in universities web pages and the importance of developing web pages for universities. This result reveals that respondents who believe in the importance of developing web pages for universities do not necessarily prefer animated pictures in these web pages. On the other hand, the table shows that the same respondents prefer graphics in these web pages.

\subsection{Items (Variables) of Interface Design and Usability}

The descriptive statistics of the 14 items of the web pages interface design and usability are shown in Table 3 . The number of observations $(\mathrm{N})$, means, mean standard errors, standard deviations, and variances is shown in Table 3. Low variances in the table show continuous data and hence suggest normal distribution of the data. The analysis of variance (ANOVA) of the variables is shown in Table 4. Only variables that showed significant differences among universities web pages are displayed. Navigation of the web pages, location tracking, hyperlinks semantics, animated pictures effect on the web pages, and icons (alone) organization did not show significant difference in the universities web pages with regards to those variables and hence they are not displayed in the table.

However, there are significant differences among the universities web pages regarding the rest of the variables. Duncan's multiple range test (Table 5) was used to arrange these variables in significantly different groups. Table 5 shows that the prototype web pages were grouped in the best group in almost all the variables showed in the table. This reveals that the prototype was almost the best among the other universities web pages.

Table 6 shows the correlation coefficients between the 14 variables studied. The web pages color amount has no significant correlation with any of the variables of the web pages studied. The web pages contrast against the background showed significant positive correlation with the web pages icons and text organization, color and graphics consistency, navigation, location tracking, and forms organization and helpfulness.

However, the contrast against the background showed no significant correlation with the web pages animated pictures effect and icons (alone) organization. The web pages graphics information provision has significant positive correlation with all the other variables studied. Specifically, it showed high positive correlation with the web pages hyperlinks semantics (Table 6). Table 6 shows that web pages color and graphics feel of consistency has positive significant correlation with most of the variables studied. However, it has no significant correlation with the text (alone) and icons (alone) organization but has high positive significant correlation with the icons

Table 3. Number of observations, means, standard errors, standard deviations, and variances of the 14 items (variables) of the universities web pages.

\begin{tabular}{|c|c|c|c|c|c|}
\hline Item (variable) & Number of observation & Mean & Standard error & Standard deviation & Variance \\
\hline Color amount & 292 & 2.90 & 0.05 & 0.78 & 0.60 \\
\hline Contrast against the background & 294 & 3.29 & 0.06 & 1.05 & 1.10 \\
\hline Graphics information provision & 290 & 3.27 & 0.05 & 0.84 & 0.71 \\
\hline Color and graphics feel of consistency & 295 & 3.12 & 0.05 & 0.86 & 0.73 \\
\hline Navigation & 295 & 3.69 & 0.05 & 0.94 & 0.89 \\
\hline Location tracking inside the web pages & 294 & 3.54 & 0.06 & 0.97 & 0.94 \\
\hline Hyperlinks (hotspot) semantics & 295 & 3.56 & 0.06 & 1.01 & 1.02 \\
\hline Forms organization and helpfulness & 290 & 3.38 & 0.05 & 0.87 & 0.75 \\
\hline Animated pictures effect on web pages look & 290 & 3.61 & 0.05 & 0.94 & 0.88 \\
\hline Text (alone) organization and design & 290 & 3.03 & 0.06 & 1.00 & 1.01 \\
\hline Icons (alone) organization and design & 293 & 3.27 & 0.06 & 1.00 & 0.99 \\
\hline Icons and text organization and design & 294 & 3.62 & 0.05 & 0.90 & 0.80 \\
\hline Multimedia preference & 294 & 3.09 & 0.06 & 0.99 & 0.99 \\
\hline Universities web pages ranking & 280 & 2.97 & 0.08 & 1.40 & 1.96 \\
\hline
\end{tabular}


Table 4. Analysis of variance (ANOVA) tables of the five universities for the 35 items (variables) of the web pages studied ${ }^{\mathrm{a}}$.

\begin{tabular}{|c|c|c|c|c|c|c|}
\hline Item (variable) & & df & Sum of square & Mean square & F-value & $p>\mathrm{F}$ \\
\hline \multicolumn{7}{|l|}{ Colour amount } \\
\hline & Between groups & 4 & 7.422 & 1.856 & 3.172 & $0.014^{* * * *}$ \\
\hline & Within groups & 287 & 167.893 & 0.585 & & \\
\hline & Total & 291 & 175.315 & & & \\
\hline \multicolumn{7}{|c|}{ Contrast against the background } \\
\hline & Between groups & 4 & 18.673 & 4.668 & 4.435 & $0.002^{* * *+}$ \\
\hline & Within groups & 289 & 304.171 & 1.052 & & \\
\hline & Total & 293 & 322.844 & & & \\
\hline \multicolumn{7}{|c|}{ Graphics information provision } \\
\hline & Between groups & 4 & 11.977 & 2.994 & 4.431 & $0.002^{* * *}$ \\
\hline & Within groups & 285 & 192.578 & 0.676 & & \\
\hline & Total & 289 & 204.555 & & & \\
\hline \multicolumn{7}{|c|}{ Colour and graphics feel of consistency } \\
\hline & Between groups & 4 & 14.590 & 3.647 & 5.262 & $0.000^{* * * *}$ \\
\hline & Within groups & 290 & 201.017 & 0.693 & & \\
\hline & Total & 294 & 215.607 & & & \\
\hline \multicolumn{7}{|c|}{ Forms organization and helpfulness } \\
\hline & Between groups & 4 & 5.876 & 1.469 & 1.973 & $0.099^{*}$ \\
\hline & Within groups & 285 & 212.155 & 0.744 & & \\
\hline & Total & 289 & 218.031 & & & \\
\hline \multicolumn{7}{|c|}{ Text (alone) organization and design } \\
\hline & Between groups & 4 & 9.103 & 2.276 & 2.296 & $0.059^{*}$ \\
\hline & Within groups & 285 & 282.552 & 0.991 & & \\
\hline & Total & 289 & 291.655 & & & \\
\hline \multicolumn{7}{|c|}{ Icons and text organization and design } \\
\hline & Between groups & 4 & 9.526 & 2.382 & 3.048 & $0.017^{* *}$ \\
\hline & Within groups & 289 & 225.807 & 0.781 & & \\
\hline & Total & 293 & 235.333 & & & \\
\hline \multicolumn{7}{|c|}{ Multimedia preference } \\
\hline & Between groups & 4 & 10.285 & 2.571 & 2.671 & $0.032^{* *}$ \\
\hline & Within groups & 289 & 278.236 & 0.963 & & \\
\hline & Total & 293 & 288.520 & & & \\
\hline \multicolumn{7}{|c|}{ Universities web pages ranking } \\
\hline & Between groups & 4 & 27.086 & 6.771 & 3.584 & $0.007^{* * * *}$ \\
\hline & Within groups & 275 & 519.625 & 1.890 & & \\
\hline & Total & 279 & 546.711 & & & \\
\hline
\end{tabular}

\footnotetext{
${ }^{* * * *}$ : Significant at 0.01 level of probability. ${ }^{* *}:$ Significant at 0.05 level of probability. ${ }^{*}:$ Significant at 0.10 level of probability. ${ }^{\text {a }}$ : Only significant variables are displayed.
} 
Table 5. Grouping of the five universities for the 35 items (variables) studied according to Duncan’s multiple range test ${ }^{\mathrm{d}}$.

\begin{tabular}{|c|c|c|c|c|c|c|c|c|c|c|c|}
\hline & $\begin{array}{l}\text { Colour } \\
\text { amount }\end{array}$ & $\begin{array}{l}\text { Contrast } \\
\text { against } \\
\text { the back } \\
\text { ground }\end{array}$ & $\begin{array}{l}\text { Graphics } \\
\text { information } \\
\text { provision }\end{array}$ & $\begin{array}{l}\text { Colour } \\
\text { and } \\
\text { graphics } \\
\text { feel of } \\
\text { consistency }\end{array}$ & Navigation & $\begin{array}{c}\text { Hyperlink } \\
\text { n (hotspot) } \\
\text { semantics }\end{array}$ & $\begin{array}{l}\text { Forms } \\
\text { organization } \\
\text { and } \\
\text { helpfulness }\end{array}$ & $\begin{array}{l}\text { Text (alone) } \\
\text { organization } \\
\text { and design }\end{array}$ & $\begin{array}{c}\text { Icons } \\
\text { and text } \\
\text { organization } \\
\text { and design }\end{array}$ & $\begin{array}{l}\text { Multi-media } \\
\text { n preference }\end{array}$ & $\begin{array}{l}\text { Universities } \\
\text { web pages } \\
\text { ranking }\end{array}$ \\
\hline Univ1 & $2.74^{\mathrm{a}}$ & $3.12^{\mathrm{a}}$ & $3.12^{\mathrm{ab}}$ & $3.19^{\mathrm{bc}}$ & $3.73^{\mathrm{ab}}$ & $3.37^{\mathrm{a}}$ & $3.38^{\mathrm{ab}}$ & $3.19^{\mathrm{b}}$ & $3.36^{\mathrm{a}}$ & $3.02^{\mathrm{ab}}$ & $2.95^{\mathrm{b}}$ \\
\hline Univ2 & $2.91^{\mathrm{ab}}$ & $3.58^{\mathrm{b}}$ & $3.34^{\mathrm{bc}}$ & $3.36^{\mathrm{c}}$ & $3.78^{\mathrm{ab}}$ & $3.59^{\mathrm{ab}}$ & $3.40^{\mathrm{ab}}$ & $2.95^{\mathrm{ab}}$ & $3.80^{\mathrm{b}}$ & $3.29^{\mathrm{b}}$ & $3.39^{\mathrm{b}}$ \\
\hline Univ3 & $3.15^{\mathrm{b}}$ & $3.24^{\mathrm{ab}}$ & $3.30^{\mathrm{bc}}$ & $2.98^{\mathrm{ab}}$ & $3.66^{\mathrm{ab}}$ & $3.59^{\mathrm{ab}}$ & $3.38^{\mathrm{ab}}$ & $3.16^{\mathrm{b}}$ & $3.58^{\mathrm{ab}}$ & $3.20^{\mathrm{b}}$ & $3.00^{\mathrm{b}}$ \\
\hline Univ4 & $2.73^{\mathrm{a}}$ & $2.95^{\mathrm{a}}$ & $2.98^{\mathrm{a}}$ & $2.76^{\mathrm{a}}$ & $3.44^{\mathrm{a}}$ & $3.42^{\mathrm{ab}}$ & $3.14^{\mathrm{a}}$ & $2.72^{\mathrm{a}}$ & $3.53^{\mathrm{ab}}$ & $2.76^{\mathrm{a}}$ & $2.43^{\mathrm{a}}$ \\
\hline Prototype & $2.98^{\mathrm{ab}}$ & $3.59^{\mathrm{b}}$ & $3.58^{\mathrm{c}}$ & $3.32^{\mathrm{c}}$ & $3.83^{\mathrm{b}}$ & $3.80^{\mathrm{b}}$ & $3.59^{\mathrm{b}}$ & $3.16^{\mathrm{b}}$ & $3.84^{\mathrm{b}}$ & $3.19^{\mathrm{b}}$ & $3.07^{\mathrm{b}}$ \\
\hline
\end{tabular}

${ }^{\mathrm{d}}$ Means with the same letters indicate no significant difference from each other at the 0.05 probability level as determined by DMRT.

Table 6. Correlation coefficients of the 14 items (variables) of the universities web pages design and usability ${ }^{\mathrm{a}}$.

\begin{tabular}{|c|c|c|c|c|c|c|c|c|c|c|c|c|c|}
\hline & 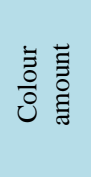 & 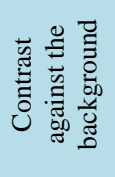 & 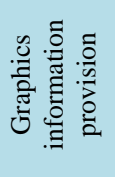 & 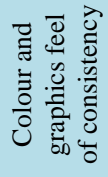 & 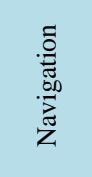 & 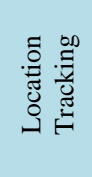 & 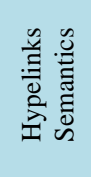 & 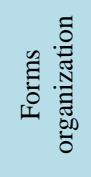 & 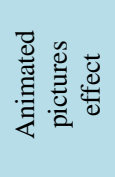 & 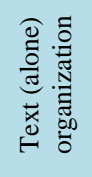 & 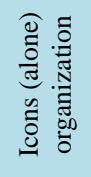 & 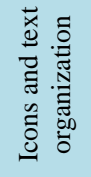 & 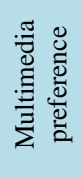 \\
\hline $\begin{array}{c}\text { Contrast } \\
\text { against the } \\
\text { background }\end{array}$ & 0.05 & & & & & & & & & & & & \\
\hline $\begin{array}{l}\text { Graphics } \\
\text { information } \\
\text { provision }\end{array}$ & 0.11 & $0.28^{* * *}$ & & & & & & & & & & & \\
\hline $\begin{array}{l}\text { Colour and } \\
\text { graphics } \\
\text { feel of } \\
\text { consistency }\end{array}$ & 0.01 & $0.33^{* * *}$ & $0.27^{* *}$ & & & & & & & & & & \\
\hline Navigation & 0.09 & $0.28^{* * *}$ & - & $0.14^{*}$ & & & & & & & & & \\
\hline $\begin{array}{l}\text { Location } \\
\text { Tracking }\end{array}$ & 0.05 & $0.28^{* *}$ & $0.25^{* *}$ & $0.26^{* *}$ & $0.41^{* *}$ & & & & & & & & \\
\hline $\begin{array}{l}\text { Hypelinks } \\
\text { Semantics }\end{array}$ & 0.03 & $0.21^{* *}$ & $0.34^{* *}$ & $0.21^{* *}$ & $0.33^{* *}$ & $0.40^{* *}$ & & & & & & & \\
\hline $\begin{array}{c}\text { Forms } \\
\text { organization }\end{array}$ & -0.04 & $0.27^{* *}$ & $0.23^{* *}$ & $0.30^{* *}$ & $0.33^{* *}$ & $0.41^{* *}$ & $0.37^{* *}$ & & & & & & \\
\hline $\begin{array}{c}\text { Animated } \\
\text { pictures } \\
\text { effect }\end{array}$ & 0.00 & 0.13 & - & $0.20^{* *}$ & 0.10 & $0.31^{* *}$ & $0.22^{* *}$ & $0.31^{* *}$ & & & & & \\
\hline $\begin{array}{l}\text { Text (alone) } \\
\text { organization }\end{array}$ & 0.01 & $0.20^{* *}$ & $0.16^{* *}$ & 0.11 & $0.22^{* *}$ & $0.29^{* *}$ & $0.26^{* *}$ & $0.41^{* *}$ & $0.18^{* *}$ & & & & \\
\hline $\begin{array}{c}\text { Icons (alone) } \\
\text { organization }\end{array}$ & 0.07 & 0.09 & $0.21^{* *}$ & 0.11 & 0.11 & - & $0.27^{* *}$ & $0.21^{* *}$ & $0.24^{* *}$ & $0.17^{*}$ & & & \\
\hline $\begin{array}{c}\text { Icons } \\
\text { and text } \\
\text { organization }\end{array}$ & 0.06 & $0.35^{* *}$ & $0.28^{* *}$ & $0.33^{* *}$ & $0.32^{* *}$ & $0.44^{* *}$ & $0.26^{* *}$ & $0.26^{* *}$ & $0.35^{* *}$ & - & $0.27^{* *}$ & & \\
\hline $\begin{array}{l}\text { Multimedia } \\
\text { preference }\end{array}$ & 0.13 & $0.21^{* *}$ & $0.20^{* *}$ & $0.20^{* *}$ & 0.11 & $0.18^{* *}$ & $0.20^{* *}$ & $0.29^{* *}$ & - & $0.35^{* *}$ & $0.24^{* *}$ & - & \\
\hline $\begin{array}{l}\text { Universities } \\
\text { web pages } \\
\text { ranking }\end{array}$ & 0.11 & $0.15^{*}$ & $0.15^{*}$ & $0.19^{* *}$ & - & 0.03 & 0.10 & $0.17^{*}$ & 0.13 & 0.09 & $0.18^{*}$ & $0.18^{* *}$ & $0.27^{* *}$ \\
\hline
\end{tabular}


and text together organization and helpfulness. Navigation of the web pages has significant positive correlation with all the variables studied except the web pages icons (alone) organization and the multimedia preferences in the universities web pages. Location tracking and hyperlinks semantics showed significant positive correlation (separately) with almost all the other variables studied except the ranking of the universities web pages. This result indicated that the ranking of the web pages of the universities did not rely much on these two variables. The web pages forms organization has significant positive correlation with the rest of the variables studied. Forms organization associated significantly with the ranking of the universities web pages. The animated pictures effect on the web pages showed significant positive correlation with the web pages text (alone), icons (alone), and icons and text (together) organization and helpfulness. However, animated pictures have no significant correlation with the ranking of the web pages. Text (alone) organization has significant positive correlation with the icons alone organization and multimedia preferences in the web pages of the universities. However, text (alone) has no significant correlation with the ranking of the universities web pages. Icons (alone) organization has significant positive correlation with the icons and text (together) organization, multimedia preference, and the web pages ranking. Icons and text (together) organization and multimedia preference have significant positive correlation (separately) with the ranking of the universities pages.

\subsection{Regression Analysis}

Multiple linear regression results are shown in Table 7. The ANOVA (analysis of variance) table for regression shows that the model was significant at the 0.01 probability level, indicating that the contribution of independent variables coefficients were not equal to zero (alternate hypothesis). The table also shows that multimedia preference in the universities web pages contributed highly and significantly to the model. However, some regression analysis procedures were used, including, forward selection, backward elimination, and stepwise selection. Maximum coefficient of determination $\left(\mathrm{R}^{2}\right)$ was achieved by including specific number of independent variables.

Table 7. Linear regression analysis between universities web pages ranking and other items (variables) of web pages design and usability.

\begin{tabular}{|c|c|c|c|c|c|c|}
\hline Source & Degrees of freedom & Sum of square & Mean square & \multicolumn{2}{|l|}{$\mathrm{F}$} & $p>F$ \\
\hline Regression & 13 & 70.00086 & 5.384682 & \multicolumn{2}{|l|}{7.26} & 0.0001 \\
\hline Error & 243 & 180.1159 & \multirow[t]{2}{*}{0.741218} & & & \\
\hline Total & 256 & 250.1167 & & & & \\
\hline \multicolumn{2}{|c|}{ Variable } & Parameter estimate & Standard error & Sum of squares & $\mathrm{F}$ & $p>\mathrm{F}$ \\
\hline \multicolumn{2}{|c|}{ Intercept } & 1.061532 & 0.440591 & 4.302695 & 5.80 & 0.0167 \\
\hline \multicolumn{2}{|c|}{ Color amount } & 0.027230 & 0.075147 & 0.097328 & 0.13 & 0.7174 \\
\hline \multicolumn{2}{|c|}{ Contrast against the background } & -0.030090 & 0.059111 & 0.192028 & 0.26 & 0.6112 \\
\hline \multicolumn{2}{|c|}{ Graphics information provision } & 0.068228 & 0.074656 & 0.619078 & 0.84 & 0.3617 \\
\hline \multicolumn{2}{|c|}{ Color and graphics feel of consistency } & -0.030560 & 0.071732 & 0.134551 & 0.18 & 0.6704 \\
\hline \multicolumn{2}{|c|}{ General navigation } & 0.069340 & 0.068237 & 0.765360 & 1.03 & 0.3106 \\
\hline \multicolumn{2}{|c|}{ Location tracking } & -0.064310 & 0.069323 & 0.637798 & 0.86 & 0.3545 \\
\hline \multicolumn{2}{|c|}{ Hyperlinks (hotspots) semantics } & 0.121541 & 0.073557 & 2.023700 & 2.73 & 0.0998 \\
\hline \multicolumn{2}{|c|}{ Forms organization and helpfulness } & 0.026652 & 0.070631 & 0.105537 & 0.14 & 0.7063 \\
\hline \multicolumn{2}{|c|}{ Animated pictures } & -0.055670 & 0.089501 & 0.286755 & 0.39 & 0.5345 \\
\hline \multicolumn{2}{|c|}{ Text (alone) organization and design } & -0.109380 & 0.064121 & 2.157001 & 2.91 & 0.0893 \\
\hline \multicolumn{2}{|c|}{ Icons (alone) organization and design } & 0.200612 & 0.057933 & 8.888093 & 11.99 & 0.0006 \\
\hline \multicolumn{2}{|c|}{ Icons and text organization and design } & -0.018650 & 0.060757 & 0.069868 & 0.09 & 0.7591 \\
\hline \multicolumn{2}{|c|}{ Multimedia preference } & 0.416697 & 0.073722 & 23.68064 & 31.95 & 0.0001 \\
\hline
\end{tabular}


Table 8 shows a summary of forward selection procedure for the dependent variable universities web pages ranking. The procedure showed that only eight independent variables contributed significantly to the model. However, universities web pages multimedia preference and icons (alone) organization and design were contributed significantly to the model. The forward selection begins with the most independent variable contributing highly to the model and advances to the next most contributing one till it reaches a satisfactory model.

Unlike the forward selection, backward elimination begins with the complete model including all the independent variables and then started to eliminate the most non-significant variable in the model considering its F-value, then proceed to the next most non-significant one. Table 9 shows a summary of the backward elimination procedure. As seen in the table, nine variables were removed from the model. This indicated that these 9 variables did not contribute significantly to the model (in this order) as the rest of the variables did.

The forward selection and backward elimination adds and eliminates (respectively) independent variables to (from) the model regardless of what variables are already outside or existing in the model. Stepwise selection reexamines at every stage the regression of the variables incorporated into the model in previous stages. A variable which might have been the best single variable to enter the model at an early stage, might at later stage, be superfluous because of the relationships between it and other variables now in the regression model [34]. Table 10 shows a summary of stepwise selection regression procedure model which included only four variables that were significantly contributed to the model at the 0.15 probability level. That is to say, universities web pages multimedia preference, icons (alone) organization, text (alone) organization, and hyperlinks (hotspots) semantics were the four most independent variables contributing to the model significantly.

Coefficient of determination $\left(\mathrm{R}^{2}\right)$ measures the proportion of total sum of squares of the variables that is explained by the regression line. It is a measure of how closely the points (observation) fit the least square line. Consequently, the line that has maximum $\mathrm{R}^{2}$ represents the best fitting line [36]. Table 11 shows the maxi-

Table 8. Summary of forward selection procedure for dependent variable universities web pages ranking.

\begin{tabular}{ccccc}
\hline Step & Variable entered & Number in & Partial $\mathrm{R}^{2}$ & $P>\mathrm{F}$ \\
\hline 1 & Multimedia preference & 1 & 0.2132 & 0.0001 \\
2 & Icons (alone) organization and design & 2 & 0.0401 & 0.0003 \\
3 & Text (alone) organization and design & 3 & 0.0073 & 0.1151 \\
4 & Hyperlinks Semantics & 4 & 0.0094 & 0.0736 \\
5 & Location Tracking & 5 & 0.0021 & 0.3959 \\
6 & Navigation & 6 & 0.0019 & 0.4177 \\
7 & Graphics information provision & 7 & 0.0017 & 0.4511 \\
\hline
\end{tabular}

Table 9. Summary of backward elimination procedure for dependent variable universities web pages ranking.

\begin{tabular}{|c|c|c|c|c|}
\hline Step & Variable removed & Number in & Partial $\mathrm{R}^{2}$ & $P>\mathrm{F}$ \\
\hline 1 & Icons and text organization & 12 & 0.0003 & 0.7591 \\
\hline 2 & Color amount & 11 & 0.0004 & 0.7161 \\
\hline 3 & Forms organization & 10 & 0.0003 & 0.7426 \\
\hline 4 & Color and graphics feel of consistency & 9 & 0.0006 & 0.6585 \\
\hline 5 & Contrast against the background & 8 & 0.0009 & 0.5751 \\
\hline 6 & Animated pictures effect & 7 & 0.0017 & 0.4466 \\
\hline 7 & Graphics information provision & 6 & 0.0017 & 0.4511 \\
\hline 8 & Navigation & 5 & 0.0019 & 0.4177 \\
\hline 9 & Location tracking & 4 & 0.0021 & 0.3959 \\
\hline
\end{tabular}


Table 10. Summary of stepwise procedure for dependent variable universities web pages ranking ${ }^{a}$.

\begin{tabular}{cccccc}
\hline Step & Variable entered/removed & Number in & Partial $\mathrm{R}^{2}$ & Model R $^{2}$ & $P>\mathrm{F}$ \\
\hline 1 & Multimedia preference & 1 & 0.2132 & 0.2132 & 0.0001 \\
2 & Icons (alone) organization and design & 2 & 0.0401 & 0.2534 & 0.0003 \\
3 & Text (alone) organization and design & 3 & 0.0073 & 0.2607 & 0.1151 \\
4 & Hyperlinks semantic & 4 & 0.0094 & 0.2700 & 0.0736 \\
\hline
\end{tabular}

${ }^{a}$ : All variables in the model are significant at 0.15 probability level.

Table 11. $\mathrm{R}^{2}$ of single and/or combination of different independent variable (s) with dependent variable universities web pages ranking.

\begin{tabular}{|c|c|c|}
\hline Number of variables in the model & Independent variable (s) & $\mathrm{R}^{2}$ \\
\hline 1 & Multimedia preference & 0.2132491 \\
\hline 1 & Icons (alone) organization & 0.084938 \\
\hline 1 & Hyperlinks semantics & 0.055802 \\
\hline 2 & Icons (alone) organization and design and multimedia preference & 0.253370 \\
\hline 2 & Hyperlinks semantics and multimedia preference & 0.222795 \\
\hline 2 & Navigation and multimedia preference & 0.218554 \\
\hline 3 & $\begin{array}{l}\text { Text (alone) organization and design and icons (alone) } \\
\text { organization and design and multimedia preference }\end{array}$ & 0.260674 \\
\hline 3 & $\begin{array}{l}\text { Hyperlinks semantics and icons (alone) } \\
\text { organization and design and multimedia preference }\end{array}$ & 0.259198 \\
\hline 3 & $\begin{array}{l}\text { Color amount and icons (alone) organization } \\
\text { and design and multimedia preference }\end{array}$ & 0.256156 \\
\hline 4 & $\begin{array}{l}\text { Hyperlinks semantics and text (alone) organization pages } \\
\text { and icons (alone) organization and design and multimedia preference }\end{array}$ & 0.270027 \\
\hline 4 & $\begin{array}{l}\text { Navigation and text (alone) organization pages and icons (alone) } \\
\text { organization and design and multimedia preference }\end{array}$ & 0.263917 \\
\hline 4 & $\begin{array}{l}\text { Graphics information provision and text (alone) organization } \\
\text { pages and icons (alone) organization and design and multimedia preference }\end{array}$ & 0.263123 \\
\hline 5 & $\begin{array}{l}\text { Location tracking and hyperlinks semantics and text (alone) organization } \\
\text { and icons (alone) organization and design and multimedia preference }\end{array}$ & 0.272125 \\
\hline 5 & $\begin{array}{l}\text { Graphics information provision and hyperlinks semantics and text } \\
\text { (alone) organization pages and icons (alone) organization } \\
\text { and design and multimedia preference }\end{array}$ & 0.271217 \\
\hline 5 & $\begin{array}{l}\text { Navigation and hyperlinks semantics and text (alone) organization pages } \\
\text { and icons (alone) organization and design and multimedia preference }\end{array}$ & 0.271186 \\
\hline
\end{tabular}

mum $\mathrm{R}^{2}$ that is attained with one independent variable, two independent variables, and so on till 13 independent variables. This might indicate the ranking importance of an independent variable as a single or in combination with other independent variables to universities web pages ranking. The results showed that the universities web pages location tracking, hyperlinks semantics, text (alone) organization, icons (alone) organization, and design, and multimedia preferences were among the first five variables (items) that contributed significantly to the universities web pages ranking. However, limitation to $\mathrm{R}^{2}$ is that the addition of an irrelevant independent variable to the regression model will increase $\mathrm{R}^{2}$ even though the irrelevant variable is not related to the other variables in the model [36]. The assumption of this model is that all the variables (items) have been estimated precisely.

The results of Tables 7-11 suggest that, some independent variables significantly contributed to the regression model and others did not. For a single independent variable, multimedia preference of the universities web pages gave the most significant contribution to the dependent variable universities web pages ranking (Table 11). For 
two independent variables, icons (alone) organization and design and multimedia preference of the universities web pages gave the most significant contribution to the dependent variable universities web pages ranking. For three independent variables, the universities web pages text (alone) organization and design, icons (alone) organization and design, and multimedia preference gave the most significant contribution to the dependent variable universities web pages ranking (Table 11).

\section{Conclusions}

From the discussion, some important conclusions and findings concerning both users (respondents) and items (variables) of the web pages of the universities [37] were unveiled. These conclusions and findings can be summarized as follows:

1. Respondents who were frequent in using computers did not prefer animated pictures in universities web pages (Table 2).

2. Respondents who frequently access the Internet believe that it is important to develop web pages for universities (Table 2).

3. Respondents who were well exposed to computer did not prefer music and animation in the universities web pages (Table 2).

4. There were significant differences between the universities web pages regarding most of the variables studied (Table 4).

5. The prototype which was developed according to a scientific methodology was proved to be better than most of the other universities web pages (Table 5).

6. Good contrast against the background of the web pages made the navigation of the web pages more convenient (Table 6).

7. Good design of graphics made the icons and hyperlinks meaningful and had metaphoric dimensions (Table 6).

8. The usage of the icons and text together in the universities web pages design was proved to be better than the usage of the text alone or the icons alone (Table 6).

9. Multimedia in the web pages, the web pages, icons organization and design, the web pages text organization and design, and hyperlinks semantics in the web pages independently and separately contributed significantly (in this order) to the ranking of the universities web pages (Table 7).

10. The best five items of web pages design and usability that together formed the most significant model were: location tracking, hyperlinks semantics, text (alone) organization and design, icons (alone) organization and design, and multimedia preference (Table 11).

\section{Recommendations for Future Work}

1. Further studies can be done to increase the validity and reliability of the questionnaire used in this study. This can be achieved by increasing and randomizing the sample of the test users (respondents), increasing the steps of the scale (e.g. 10 points scale), and increasing the number of the questions used in the questionnaire.

2. In further studies, it is suggested that the questions of the questionnaire can be improved by being more specific and adhere to the scale designed for that. General questions can yield confounding results. For one item or variable of interface usability there may be several questions instead of only one or few.

3. In this study, only one sample group was used. In future work, the sample users (respondents) can be divided into two groups: users and experts. More sophisticated scale (e.g. 10 points scale) can be constructed for expert users (respondents). In 10 points scale for instance, expert users can better distinguish the different levels (points) of a single question which can yield a wide range of data which could be better analyzed statistically.

4. Additional statistical models can rigorously analyze the usability of the web pages and hence more valid and verified conclusions can be achieved.

\section{Acknowledgements}

The authors would like to thank Princess Nourah bint Abdulrahman University Riyadh, KSA, for assistance they rendered concerning this work. 


\section{References}

[1] Jacko, J.A. (2012) The human-Computer Interaction Handbook: Fundamentals, Evolving Technologies, and Emerging Applications. CRC Press, Florida, 1518. http://dx.doi.org/10.1201/b11963

[2] Nielsen, J. (1993) Usability Engineering. Academic Press, Inc., Harcourt Brace \& Company, San Diego, USA.

[3] Landseadel, P. (1994) Methodologies in User Interface Design. IEEE Electronic Library, No. 0-7803-1910-9/94. http://dx.doi.org/10.1109/autest.1994.381557

[4] Myers, B.A. and Rosson, M.B. (1992) Survey on User Interface Programming. CHI'92 Proceedings of the SIGCHI Conference on Human Factors in Computing Systems, Monterey, CA, 3-7 May 1992, 195-202. http://dx.doi.org/10.1145/142750.142789

[5] Norman, D.A. (2010) Natural User Interfaces Are Not Natural. Interactions, 17, No. 3. http://dx.doi.org/10.1145/1744161.1744163

[6] Shneiderman, B., Kent, L. Norman, C.P., Benjamin, B., Bederson, D.A. and Golbeck, J. (2013) 30 Years at the University of Maryland's Human-Computer Interaction Lab (HCIL). Interactions, 20, 50-57. http://dx.doi.org/10.1145/2508061

[7] Nielsen, J. (2013) Usability 101: Introduction to Usability. Jakob Nielsen’s Alertbox, 25.

[8] Davis, P. and Shipman, F. (2011) Learning Usability Assessment Models for Web Sites. Proceedings of the 16th International Conference on Intelligent User Interfaces, Palo Alto, 13-16 February 2011, 195-204. http://dx.doi.org/10.1145/1943403.1943433

[9] Buckingham, S. and McKnight, C. (1997) Word Wide Web Usability: Introduction to This Special Issue. International Journal of Human-Computer Studies, 47, 1-4. http://dx.doi.org/10.1006/ijhc.1997.0132

[10] Shneiderman, B. (1997) Designing Information-Abundant Web Sites: Issues and Recommendations. International Journal of Human-Computer Studies, 47, 5-30. http://dx.doi.org/10.1006/ijhc.1997.0127

[11] Lee, Y. and Kozar, K. (2012) Understanding of Website Usability: Specifying and Measuring Constructs and Their Relationships. Decision Support Systems, 52, 450-463. http://dx.doi.org/10.1016/j.dss.2011.10.004

[12] Bieber, M., Vitali, F., Ashman, H., Balasubramanian, V. and Oinas-Kukkonen, H. (1997) Fourth Generation Hypermedia: Some Missing Links for the World Wide Web. International Journal of Human-Computer Studies, 47, 31-66. http://dx.doi.org/10.1006/ijhc.1997.0130

[13] Smith, P.A., Newman, I.A. and Parks, L.M. (1997) Virtual Hierarchies and Virtual Networks: Some Lessons from Hypermedia Usability Research Applied to the World Wide Web. International Journal of Human-Computer Studies, 47, 67-95. http://dx.doi.org/10.1006/ijhc.1997.0128

[14] Erskine, L.E., Carter-Tod, D. and Burton, J.K. (1997) Dialogical Techniques for the Design of Web Sites. International Journal of Human-Computer Studies, 47, 169-196. http://dx.doi.org/10.1006/ijhc.1997.0129

[15] Thimbleby, H. (1997) Gentler: A Tool for Systematic Web Authoring. International Journal of Human-Computer Studies, 47, 139-168. http://dx.doi.org/10.1006/ijhc.1997.0131

[16] Benyon, D., Stone, D. and Woodroffe, M. (1997) Experience with Developing Multimedia Courseware for the World Wide Web: The Need for Better Tools and Clear Pedagogy. International Journal of Human-Computer Studies, 47, 197-218. http://dx.doi.org/10.1006/ijhc.1997.0126

[17] Koved, L. and Shneiderman, B. (1986) Embedded Menus: Selecting Items in Context. Communications of the ACM, 29, 312-318. http://dx.doi.org/10.1145/5684.5687

[18] Shneiderman, B. and Kearsley, G. (1989) Hypertext Hands-On: An Introduction to a New Way of Organising and Accessing Information. Addison-Wesley, Reading.

[19] Norman, K. (1991) The Psychology of Menu Selection: Designing Cognitive Control at the Human/Computer Interface. Ablex, Norwood.

[20] Rivlin, E., Rotafogo, R. and Shneiderman, B. (1994) Navigating in Hyperspace: Designs for a Structure-Based Toolbox. Communications of the ACM, 37, 87-96. http://dx.doi.org/10.1145/175235.175242

[21] Isakowitz, T., Stohr, E.A. and Balasubramanian, P. (1995) RMM: A Methodology for Hypermedia Design. Communications of the ACM, 38, 34-44. http://dx.doi.org/10.1145/208344.208346

[22] Belkin, N.J. and Croft, B.W. (1992) Information Filtering and Information Retrieval: Two Sides of the Same Coin? Communications of the ACM, 35, 29-38. http://dx.doi.org/10.1145/138859.138861

[23] Marchionini, G. (1989) Making the Transition from Print to Electronic Encyclopaedia: Adaptation of Mental Models. International Journal of Man-Machine Studies, 30, 591-618. http://dx.doi.org/10.1016/S0020-7373(89)80012-4

[24] Staggers, N. (1993) Impact of Screen Density on Clinical Nurses’ Computer Task Performance and Subjective Screen 
Satisfaction. International Journal of Man-Machine Studies, 39, 775-792. http://dx.doi.org/10.1006/imms.1993.1083

[25] Horton, W., Taylor, L., Ignacio, A. and Hoft, N.L. (1996) The Web Page Design Cookbook. John Wiley \& Sons, Inc., New York.

[26] Norman, D. and Nielsen, J. (2013) 10 Usability Heuristics for User Interface Design. http://www.nngroup.com/articles/ten-usability-heuristics/

[27] Bailey, J.E. and Person, S.W. (1983) Development of a Tool for Measuring and Analysing Computer User Satisfaction. Management Science, 29, 530-545. http://dx.doi.org/10.1287/mnsc.29.5.530

[28] Chin, J.P., Norman, K.L. and Shneiderman, B. (1987) Subjective User Evaluation of CF PASCAL Programming Tools. Technical Report (CAR-TR-304), Human-Computer Interaction Laboratory, University of Maryland, College Park.

[29] Chin, J.P., Virginia, A.D. and Norman, K.L. (1988) Development of an Instrument Measuring User Satisfaction of the Human-Computer Interface. Proceedings of the SIGCHI Conference on Human Factors in Computing Systems, Paris, 27 April-2 May 2013, 213-218. http://dx.doi.org/10.1145/57167.57203

[30] Ives, B., Olson, M.H. and Baroudi, J.J. (1983) The Measurement of User Information Satisfaction. Communication of the ACM, 26, 785-793. http://dx.doi.org/10.1145/358413.358430

[31] Larcker, D.F. and Lessig, V.P. (1980) Perceived Usefulness of Information: A Psychometric Examination. Decision Science, 11, 121-134. http://dx.doi.org/10.1111/j.1540-5915.1980.tb01130.x

[32] Rushinek, A. and Rushinek, S.F. (1986) What Makes User Happy? Communication of the ACM, 29, 594-598. http://dx.doi.org/10.1145/6138.6140

[33] Nunnally, J.C. (1978) Psychometric Theory. McGraw-Hill Book Company, New York.

[34] Drapper, N.R. and Smith, H. (1981) Applied Regression Analysis. John Wiley \& Sons Inc., New York.

[35] SAS Institute Inc. (1987) SAS /STATTM Guide for Personal Computers. Version 6, SAS Institute Inc., Cary.

[36] Retherfor, R.D. and Choe, M.K. (1993) Statistical Models for Causal Analysis. John Wiley \& Sons, Inc., New York. http://dx.doi.org/10.1002/9781118033135

[37] Subair, S. (2014) The Usability Engineering of the Universities Web Pages User Interfaces: A Pragmatic Approach. Princess Nourah bint Abdulrahamn University Printing Press, Riyadh, in Press. 